\title{
The Design of a Cognitive Apprenticeship to Facilitate Storytime Programming for Librarians
}

\author{
Jennifer A. Scott Brown \& Jill E. Stefaniak \\ Old Dominion University, United States
}

\begin{abstract}
The majority of research that has been conducted on structuring mentorship programs has been on career support in terms of transferring tacit and explicit knowledge from the supervisor to the protégé. While the instructional design literature touts that cognitive apprenticeships provide a great framework for constructivist and situated learning environments, little research has been done examining how much time should be allocated to the various phases of the apprenticeship framework. The purpose of this study was to explore whether the use of a cognitive apprenticeship framework could be used to mentor new librarians. Data was collected and analyzed in three phases. Phase 1 consisted of a needs assessment to determine the skills necessary for programmers to deliver a curriculum based storytime. Phase 2 data collected during the implementation of the cognitive apprenticeship included observation and reflective journals. Data collected during Phase 3 consisted of participant interviews immediately following the implementation of the cognitive apprenticeship, and three months after the conclusion of the study. All data was coded and analyzed using a phenemonological approach. The researchers found the need for flexibility when utilizing a cognitive apprenticeship model, based on participant prior knowledge and experience, the importance of the modeling and coaching stages of the model, participant desire for working with other programmers being trained.
\end{abstract}

Keywords: Situated learning; Instructional sequencing; Cognitive apprenticeship; Programming; Librarians

\section{Introduction}

The purpose of traditional mentorship is for less experienced individuals or novices to learn from more experienced individuals such as supervisors in a workplace setting (Raabe \& Beehr, 2003; Swap, Leonard, Shields, \& Abrams, 2001), and the mentor provides career and psychological support for the mentee (Higgins \& Kram, 2001). Mentoring can be traced back to the use of apprenticeships to teach technical and artisan skills such as blacksmithing, stone masonry and professionals such as lawyers and doctors for hundreds of years. Collins, Brown, and Hollum (1991) assert that the model of apprenticeship is still relevant today in terms of passing knowledge from one individual to another in order to improve efficiency and promote personal and professional growth. 
Today, mentorship is used to build and enhance an individual's career opportunities by pairing a novice with a supervisor within an organization to support the novice's personal and professional development while working for the organization (Higgins \& Kram, 2001; Joo, 2005; Raabe \& Beehr, 2003). Experts attempt to support protégés through career and psychological support. Career support can be lessons learned, contacts, or insight into the organization's values. Psychological support on the other hand is more informal and includes building a friendship relationship between the supervisor and the protégé, counseling, and having a relationship outside of the work environment (Higgins \& Kram, 2001).

\section{Literature Review}

The majority of research that has been conducted on structuring mentorship programs has been on career support for transferring tacit and explicit knowledge from the supervisor to the protégé (Higgins \& Kram, 2001; Joo, 2005; Swap et al., 2001). Mentors attempt to transfer critical information about the organization, values, norms, and often introduce their protégés to the important contacts they have made throughout their career. Higgins and Kram (2001) suggest that organizations increasingly rely more on mentoring programs to manage worker knowledge, because workers are now working in knowledge-based environments in which it is necessary to transfer important information and knowledge from an expert to a novice, or else the knowledge will be lost forever when the expert is no longer with the organization.

Kram (1983) and Newby and Heide (1992) have outlined suggested phases that the supervisor and protégé should go through in order to have a successful mentoring experience. First and foremost, the protégé should work to set goals for the mentoring relationship. It is not necessary for the mentor to be involved in this process as the protégé needs to decide exactly what they want to get out of the relationship. The protégé may work with the human resource department in order to determine their career goals and so the human resource department is able to pair the protégé with an appropriate supervisor (Kram, 1983; Newby \& Heide, 1992).

The next stage initiation. This is where the protégé is paired with the expert. Just like in consulting (Block, 2011), this is the stage where expectations of both the expert and the protége are outlined (Kram, 1983; Newby \& Heide, 1992). This is an important stage to work through because if the individuals' expectations are not aligned, the protégé and expert may need to reevaluate the relationship and determine whether or not the expert and the protégé will benefit from the relationship and whether or not it is worth moving forward (Kram, 1983; Newby \& Heide, 1992).

Following the initiation stage, the expert and protégé will move on to cultivating their relationship. According to Kram (1983), this phase of the mentoring relationship typically lasts two to five years. Protégés are typically given more complex tasks to complete. At the beginning of this phase, the expert provides a great deal of support to help the protégé complete the task. As the protégé continues to move through this phase, the amount of support he/she receives from the expert continues to fade until the protégé is able to complete similar, equally complex tasks on their own (Kram, 1983; Newby \& Heide, 1992). This phase is much like the scaffolding and support aspects of cognitive apprenticeship theory. The learner learns directly from an expert. The expert starts by modeling problem solving or metacognitive skills, and then provides the learner with similar tasks. 
The expert is available to answer questions and guide the learner through the process through scaffolding, until eventually the support is faded away and learners are able to complete complex tasks on their own. This is known as fading (Collins, Brown, et al., 1991).

Both the phases of mentoring (Kram, 1983; Newby \& Heide, 1992) and the cognitive apprenticeship model (Collins, Brown, et al., 1991) work within Vygotsky's socio-cultural theory, and more specifically his theory on zone of proximal development (Vygotsky, 1986). The zone of proximal development is the area in which an individual is able to successfully complete tasks with the aid of a more advanced individual. In the case of mentorship and cognitive apprenticeship theory, this would be with the aid of an expert. Eventually the learner is able to complete similar tasks on his or her own, without the aid of the expert.

Once the learner is able to complete the task on their own, they have either completed their training/mentoring program (in terms of a work environment) or they are ready for more complex tasks to be completed with the aid of an expert (Vygotsky, 1986). Additionally, during the cultivation stage, it is important for the expert to observe the protégé's work and provide both negative and positive feedback in a timely manner in order to praise the protégé or to correct behavior immediately. This allows the protégé to grow professionally (Collins, Brown, et al., 1991; Gilley, Gilley, \& Kouider, 2010).

The next phase of mentoring is separation. This is when the protégé begins exerting more independence and the support from the mentor begins fading drastically. The protégé gains confidence in his/her abilities and the mentor only steps in to help the protégé if the protégé requests assistance. This is a difficult transition for both the protégé and the mentor as many times if separation occurs too soon, the protégé may feel abandoned. However, if the mentor becomes too attached to the protégé, there is the possibility that the mentor may block the protégé from receiving well-deserved promotions or to exploit career opportunities because the mentor is afraid of losing the protégé (Kram, 1983; Newby \& Heide, 1992)

Finally, during the redefinition phase, the role of the protégé is redefined and the protégé's due to an increase of responsibilities. Separation is also the process in which the relationship between the protégé and the expert transitions to one of colleagues as opposed to mentorship, with the occasional counseling session when the protégé requires advice. However, over all, the mentor and protégé are seen as equals. The mentor may even consult the protégé at this point in the mentoring phase for advice (Kram, 1983; Newby \& Heide, 1992).

\section{The Use of Cognitive Apprenticeship to Enhance Mentorship}

Apprenticeships are a method of teaching that are utilized to promote one-on-one learning while working with an expert (master teacher) to solve real world tasks (Collins, Brown, \& Newman, 1987; Lave, 1988). Within the apprenticeship framework, tasks are modeled for students to observe by the expert. Throughout the duration of the apprenticeship, the expert employs a scaffolded approach by providing a lot of support and coaching at the beginning and them decreases the level of support as the apprentice gains familiarity and proficiency with the task. 
The cognitive apprenticeship learning environment consists of four dimensions: content, method, sequencing, and sociology (Collins, Hawkins, \& Carver, 1991). The contents of each of the four dimensions of the cognitive apprenticeship framework are outlined in Table 1.

Table 1. Contents of a Cognitive Apprenticeship Framework

\begin{tabular}{|c|c|}
\hline 20116 & \\
\hline & $\begin{array}{l}\text { Domain knowledge: Subject-matter-specific concepts, facts, and procedures } \\
\text { Heuristic strategies: Generally applicable techniques for accomplishing tasks } \\
\text { Control strategies: General approaches for directing one's solution process } \\
\text { Learning strategies: Knowledge about how to learn new concepts, facts, and } \\
\text { procedures }\end{array}$ \\
\hline Meth & \\
\hline $\begin{array}{l}. \\
. \\
. \\
.\end{array}$ & $\begin{array}{l}\text { Modeling: Teacher performs a task so students can observe } \\
\text { Coaching: Teacher observes and facilitates while students perform a task } \\
\text { Scaffolding: Teacher provides support to help the student perform a task } \\
\text { Articulation: Teacher encourages students to verbalize their knowledge and thinking } \\
\text { Reflection: Teacher enables students to compare their performance with that of others } \\
\text { Exploration: Teacher invites students to pose and solve their own problems }\end{array}$ \\
\hline Seque & encing \\
\hline & $\begin{array}{l}\text { Increasing complexity: Meaningful tasks gradually increasing in difficulty } \\
\text { Increasing diversity: Practice in a variety of situations to emphasize broad application } \\
\text { Global to local skills: Focus on conceptualizing the whole task before executing the } \\
\text { parts }\end{array}$ \\
\hline Sociol & logy \\
\hline & $\begin{array}{l}\text { Situated learning: Students learn in the context of working on realistic tasks } \\
\text { Community of practice: Communication about different ways to accomplish meaningful } \\
\text { tasks } \\
\text { Intrinsic motivation: Students set personal goals to seek skills and solutions } \\
\text { Cooperation: Students work together to accomplish their goals }\end{array}$ \\
\hline
\end{tabular}

Collins, A., Hawkins, J., \& Carver, S.M. (1991). A cognitive apprenticeship for disadvantaged students. In B. Means, C. Chelemer, \& M.S. Knapp (Eds.) Teaching advanced skills to at-risk students: Views from research and practice (pp. 216-243). San Francisco, CA: Josey-Bass Publishers. This material is reproduced with permission of John Wiley \& Sons, Inc.

While there is no set time regarding when to activate certain phases of the cognitive apprenticeship, most experts will integrate modeling, coaching, scaffolding, articulation, reflection, and exploration as methods. At the time of this article, no empirical research exists that has looked at the timing of when to employ these identified methods. Upon closer inspection, there is alignment between the cognitive apprenticeship framework (Collins, et al., 1989) and Newby and Heide's (1992) phases of mentorship. Figure 1 outlines the alignment between the two. 


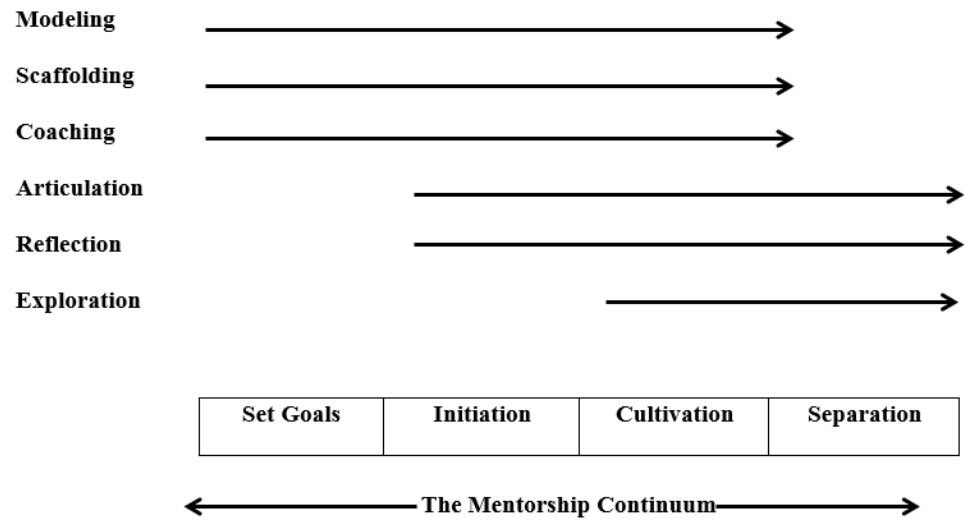

Figure 1. Alignment between Mentorship and Cognitive Apprenticeship Methodologies

\section{Purpose of the Study}

A cognitive apprenticeship framework has been developed (Collins, Brown \& Newman, 1989; Collins, 2006) outlining various content included when developing a cognitive apprenticeship; however, there is a need for an instructional design process to be developed that outlines the sequential process needed to deliver instruction utilizing a cognitive apprenticeship approach. While studies have been conducted exploring the utilization of cognitive apprenticeships to enhance teacher education and student preparation (Alger \& Kopcha, 2011; Bouta \& Paraskeva, 2013; Dennen \& Bruner, 2007; Dickey, 2008; Liu, 2005; Stewart \& Lagowski, 2003), there is a paucity of literature that has explored the implementation of cognitive apprenticeships within informal learning environments. The purpose of this study was to explore how the use of a cognitive apprenticeship framework could be used to mentor new programmers on storytime practices at local libraries.

For the purpose of this study, library programmers are individuals who provide library and storytime programs and do not hold the title of librarian. The programmers are the novices. This may be interchanged with storytime provider. Librarians are individuals who hold a master's degree in library science and hold the specific title of Librarian in the library system. The Youth and Family Services (YFS) Librarians in this library system are responsible for providing storytime training. Therefore, the Librarian is the expert in this study.

This study was guided by the following research questions:

1. How do trainees experience learning within a cognitive apprenticeship framework?

2. What challenges do librarian mentors experience while implementing a cognitive apprenticeship in an informal learning environment?

3. To what extent do cognitive apprenticeships increase confidence in planning and delivering storytimes?

4. What logistical challenges exist with implementing a cognitive apprenticeship over the course of six weeks? 


\section{Methods}

A qualitative, phenomenological study was conducted in order to determine the experiences of individuals who participated in the cognitive apprenticeship; both for the instructional designer and the new storytime programmers who were being trained to design, develop, and implement storytimes in a public library setting. Phenomenological studies are used analyze the participant's experience. Themes are identified by analyzing conversations that were transcribed during the interview stages. As trends in the analysis were identified, they were coded and categorized into broader, overarching themes (Larkin, Watts, \& Clifton, 2005).

The researchers collected multiple forms of data from the instructional designer's perspective and the programmer's perspective. For the instructional designer, reflective journals and an interview following the implementation of the cognitive apprenticeship was coded and analyzed. For the programmers, observation was utilized, a survey directly following the implementation of the cognitive apprenticeship, and again 3 months following the conclusion of the study.

Upon completion of the interviews, and the six-week cognitive apprenticeship training program, the researchers individually reviewed the open-ended responses participants provided to questions and went through a qualitative coding process to identify themes pertaining to participants' responses (Delattre, Ocler, Moulette, \& Rymeyko, 2009). The researchers conducted a peer debriefing (Willig, 2008) activity to discuss codes that were assigned. To improve the validity of this qualitative study, the researchers discussed codes until a consensus was reached.

\section{Setting}

This study took place in a large library system in southeastern Virginia that is comprised of 10 library branches. The majority of library programming that takes place in the library system are storytime programs based on an early literacy curriculum developed by the Public Library Association (PLA) and the Association for Library Services for Children (ALSC) that is used to prepare preschool participants for learning how to read. The study took place at a total of two branches, working with three separate programmers who later became responsible for delivering these curriculum based storytimes independently.

\section{Participants}

Participants comprised three library programmers, two of which had been employed by the library system previously and were promoted to a position requiring storytime programming, and the other was a library school intern. One librarian who is also an instructional designer, was responsible for designing and implementing the training during this first iteration of the cognitive apprenticeship/mentorship program.

Participant 1 was a library school intern who previously worked for a different library system providing storytime sessions for babies and toddlers. While the previous system she worked for 
had a storytime structure and programs are designed using the same early literacy curriculum, the structure of the program was different from the structure used in this study and used parent "callouts" used to educate parents on early literacy skills, focusing on how they can practice these skills at home. Participant 1 also had teaching experience that made her feel comfortable presenting a program in front of an audience.

Participant 2 was a full time programmer. She has been working in the library system for approximately ten years off and on, in various positions. She had minor experience in developing programs for library patrons, providing storytime programs for preschool outreach sites, but had no experience in delivering storytimes utilizing the system's parental callout format. Participant 2 also had teaching experience that helped prepare her for classroom management techniques and feeling comfortable presenting in front of an audience.

Participant 3 was a part time Information Specialist II and worked with the library system in various positions. Participant 3 has no teaching experience and has not developed or delivered programming prior to starting this position.

\section{Cognitive Apprenticeship Schedule}

The goal of this six week long cognitive apprenticeship/mentorship was to make storytime providers feel comfortable and confident in providing a quality, curriculum-based, early literacy storytime for patrons over the course of a six week period, and be confident in delivering their own storytime session independently. In order to accomplish this, participants had to understand how to select picture books appropriate for the age range they were delivering storytime, how to include activities that were meaningful and supported the early literacy skills, how to enthusiastically deliver storytimes, and finally, how to incorporate the parental callouts that define the early literacy skills, how they are practiced during storytime, and finally what they can do at home to practice these skills with their child. A schedule was developed to incorporate the six stages of Collins, Brown, and Hollum's (1991) cognitive apprenticeship within the six week timeframe.

\section{Procedures}

Data collection consisted of two phases. A needs assessment was conducted with a group of youth and family service librarians to ascertain the current status of storytime classes, how storytime providers are currently trained, and whether or not there was a need to streamline both the storytime classes and storytime provider training. The library system as a whole provides 78 curriculum-based, age appropriate storytimes a week that are planned around six early literacy skills defined by the Every Child Ready to Read nationwide public library initiative and include books, songs, rhymes, and activities to practice both fine and gross motor control. Each storytime series lasts six weeks, and there are five storytime series a year.

During Phase 1, nine librarians were administered a survey to provide recommendations for the development of the cognitive apprenticeship. The librarians were asked to provide insights 
regarding current mentoring (or lack thereof) practices, challenges with leading storytimes, suggested prioritization for training topics, and structure of activities. Data collected during this phase was used to inform the design of a cognitive apprenticeship to mentor novice programmers with storytime practices.

Phase 2 consisted of the design and implementation of a cognitive apprenticeship broken into four separate stages.

Stage 1: Modeling (Weeks 1-2). The focus of this stage of the apprenticeship was to model various aspects of planning and delivering a storytime program. The goal here was for the mentor (YFS Librarian) to model and explain her thought process for the structure of the storytime and how it is related to the ECRR curriculum, and the justification for the various elements included in the program. Additionally, the instructing librarian modelled the actual delivery of the storytime so the programmer could witness how the librarian interacted with children and parents, and would understand the sequence and flow as it is delivered in an actual classroom.

Administrative. The instructing librarian accessed the storytime registration list through for the storytime class that the librarian and programmer delivered together. The librarian explained to the programmer what information was relevant for creating an attendance sheet and modeled how to create attendance sheets utilizing the information gathered from registration.

Storytime Planning. The librarian modeled the process of planning and delivering a storytime class while the programmer observed and asked questions. The librarian planned their storytime classes as usual, however while doing so, she thought aloud for the programmer's benefit. For example, when choosing books and activities for the storytime, she outlined the process she followed to determine whether or not a picture book, finger play, or song was appropriate for the specific age group she was presenting to, and whether or not the book reflects an aspect of literacy standards. The librarian showed the programmer an example of the storytime class structure and explained why she chose her structure. This also gave the programmer an opportunity to ask clarifying questions.

Storytime Delivery. For the first two weeks of a storytime series, the programmer observed the instructing librarian deliver storytimes. Before delivery, the librarian encouraged the programmer to pay special attention to the defining, modeling, and assigning portions of the class. Following each class, the librarian explained the following:

- Reiterate why the structure that was utilized was chosen

- Explain why the librarian chose to veer from the plan (if any alterations were made)

- Explain the classroom management techniques that were used

- The use of the define, model, assign literacy model

Post Delivery Administrative Tasks. Following the second week, the instructing librarian modeled how to access waitlists through the registration software in order to determine who is at the top of the waitlist and who can be invited to the class. If there was room in the storytime class, she demonstrated how to contact those at the top of the waitlist and offer them a position. While completing these tasks, the librarian explained how to do each step of this process and answer any 
questions the programmer had. She also modeled how to record the attendance numbers for each storytime class.

Stage 2: Scaffolding (Weeks 3-4). During this stage of the mentorship, the YFS Librarian allows the programmer to perform tasks on their own while scaffolding and coaching the learner through the process. The mentee is encouraged to explore different books and activities to find elements that will work during storytime for the specific audience and that are aligned with the ECRR curriculum. The YFS Librarian also helps assist with articulation by asking the programmer prodding questions and justifications for why they chose certain storytime elements and linking them back to the ECRR curriculum.

Storytime Planning. During this stage of the mentoring process, the programmer was given the opportunity to plan storytimes for weeks 3-4 with the aid of the librarian. The programmer chose a variety of books, an ECRR skill and practice to model to the parents, and any supplemental activities such as songs and fingerplays. Additionally, the programmer worked within the established storytime structure developed by the librarian and programmer during weeks 1-2.

Following the planning process, the instructing librarian and the programmer scheduled a time to meet before the storytime delivery to review the programmer's book and activity selection. This was an opportunity for the programmer to reflect on the justification for selection, and for the librarian to formatively assess whether or not the programmer understood the ECRR curriculum concepts and the storytime structure adopted by the library system.

Storytime Delivery. During this stage of the process, the programmer was allowed to deliver at least half of the storytime class, with the assistance of the librarian in order for the programmer to gain experience with interacting during the program. She remained in the room while the programmer presented, and offered support as issues arose or of the programmer requested support. It is important to note that during this scaffolding stage, both during planning and delivery, the librarian provided immediate feedback whether positive or constructive in order to help the programmer correct behaviors in a timely manner.

Post Delivery Administrative Tasks. The programmer recorded program statistics based on branch procedures. The librarian provided both positive and constructive feedback to the programmer on their task performance and asked for clarifying questions regarding the programmer's experience.

Stage 3: Fading (Weeks 5-6). The focus of this stage of the cognitive apprenticeship was to allow the programmer to move away from the guidance of the librarian and plan and deliver all aspects of the storytime on his or her own. The librarian was still available for guidance when needed, continued to provide feedback, and encouraged the programmer to reflect upon programming decisions to ensure early literacy goals continued to be met.

Storytime Planning. The programmer was responsible for planning the entire storytime class including book and activity selections. The programmer provided the librarian with an outline of the storytime class and justified each element included in the program. The librarian provided both positive and constructive feedback to the programmer in terms of the storytime outline. 
Anytime the programmer's plan required revision, the librarian provided scaffolding and coaching in order to guide and encourage the programmer to reflect on the differences between their selection and the librarian's selections during the modeling stage.

Storytime Delivery. The programmer delivered the entire storytime class alone with the exception of administering the program evaluations. As this was a new task, the librarian modeled the process for administering the program evaluations while the programmer observed.

By this stage of the cognitive apprenticeship, the programmer was able to successfully deliver the storytime class, including classroom management. Following the storytime class, the librarian provided both positive and constructive feedback to the programmer regarding performance, structure, flexibility, and classroom management.

Post Delivery Administrative Tasks. The programmer recorded program statistics based on branch procedures. The librarian reviewed the program statistics to ensure that they have been recorded appropriately and provided positive and constructive feedback as necessary.

Stage 4: Separation (Following the six week series). Following the completion of the cognitive apprenticeship, the programmer is completely responsible for planning and delivering their storytime classes. Support gradually faded from the beginning of the apprenticeship until it was completely removed at the end of the apprenticeship. However, just like with mentorships, in which coaching continues following the mentee's mastery, the librarian continued to be available for guidance and feedback as necessary.

During this stage of the mentorship process, the programmer became responsible for all administrative tasks, planning and delivering all storytimes in a series. This includes the following:

- Creating attendance sheets

- Planning the structure of the program

- Evaluating and selecting materials to be used within the storytime

- Delivering the storytime to participants

- Recording program statistics

Participants who participated in the cognitive apprenticeship were asked to participate in an interview upon completion of their six-week training session and provide copies of their reflections and any instructional artifacts that they completed during the training. A second interview was conducted with the trainees three months after they completed the Storytime Basics training program to obtain feedback regarding improvements that could be made to the course.

\section{Results}

The researchers collected and analyzed data from observations, reflective journals, and interviews. They analyzed the material from all data sources and identified a number of themes that are identified and defined below: 
Organized and Prepared. Participants felt that they were more prepared and organized and prepared for delivering their storytimes after participating in the cognitive apprenticeship, instead of feeling like they were being thrown into an unfamiliar situation with no support.

Importance of Modeling. Participants felt the most valuable aspect of the cognitive apprenticeship experience was the modeling phase. This allowed the participant to not only see how to plan and implement a storytime, but to understand the reason for the structure and elements that are included in the storytime.

Collaborative Learning. Participants mentioned wanting to learn from others during the study. They not only wanted to get to know the other novices that were participating in the study, but to learn from their peers as well.

Adaptive Learning. The Librarian mentioned that one of the most time consuming aspects of the cognitive apprenticeship was adapting the coaching and structure of the cognitive apprenticeship for each participant, as they all had different levels of background knowledge and experience.

\section{Conducting a Needs Assessment: The Impetus for the Cognitive Apprenticeship}

During the needs assessment, many youth and family service librarians indicated even though they are seen as the experts in the library system where providing storytimes throughout the system are concerned, they experience challenges with classroom management and providing information to parents regarding early literacy skills and practices during the program. Part of this reason is because many of the librarians do not have formal training as educators and therefore do not have the skills necessary for teaching and keeping control of a classroom.

Training of programmers to prepare for storytime delivery varied greatly around the library system. At the minimum, programmers are only required to read the Storytime Manual that was written by the youth and family services department, followed by observing storytime classes around the system, and attending the Storytime Basics training provided by the department once a year. Some librarians were taking it upon themselves to mentor the new ISII one on one. Once the librarian feels the programmer is ready to deliver storytimes, then the programmer is placed on the storytime schedule. The librarian then observes the programmer once per series, and meets one on one with the programmer to discuss performance and provide suggestions for improvement.

The librarians indicated if anything could be changed about the storytime program, it would be better and more training for programmers, additional training on behavior management, and scheduling training during the onboarding process when the information provided in the training is most relevant to the learner. 


\section{Phase 2: Post Cognitive Apprenticeship Survey}

Directly following the cognitive apprenticeship, participants were interviewed to determine how they felt about the overall experience. Overall, participants felt more organized and prepared for delivering their storytimes. Participants believed the most important aspect of the cognitive apprenticeship was the modeling, especially in terms of delivering the early literacy callouts to caregivers:

"I didn't feel like I was thrown into it. I think I would have made a lot more mistakes. There was good constructive criticism with the coupling of the watching, helping, doing". (Participant 2)

Participant 2 is acknowledging the modeling stage with her use of the word watching, scaffolding with helping, and fading with doing. Additionally, the participant points out the mentor provided constructive criticism in an effort to improve performance and understanding.

Since the ECRR parental callouts were identified as one of the most difficult aspects of designing and delivering storytimes, the cognitive apprenticeship placed focus on this aspect of the training. When prompted to explain the most difficult aspect of the storytime, all three participants stated the placement of the callouts:

One of the things that was most helpful was um, the, the, callout, how you said the first callout was defining, the second callout is um illustrating um what the skill is and how what activity you use to implement it. And the third was kind of like the homework one. That was very helpful because you know I'm going through tis manual and I'm reading all of these things and obviously the, the first and the third are obvious as to what to put there, but the second one is kind of like... that really helped me out a lot to help me understand what is good to do there. (Participant 3)

Participant 3 is referring to the callout structure for the storytimes. The first callout is to define the early literacy skill, the second callout is to direct caregiver attention to how programmers practice the skill in storytime, and the third callout is the assign callout in which the programmer gives the caregiver suggestions for how they can continue to practice early literacy skills at home. The participant stated that she read the storytime manual and get a basic idea for where the callouts should be placed and their purpose, however, seeing it in person, along with the justification and tips for how to place the callouts within the flow of the storytime program helped the participant design and place her own callouts within the storytimes she was asked to prepare on her own.

\section{Three Month Post Cognitive Apprenticeship Survey}

Three months following the cognitive apprenticeship, two out of three of the participants were given the same interview to determine if their confidence levels increased following a storytime series in which they were independently responsible for designing and delivering a storytime. Participant 1's internship was complete with the library system and therefore was no longer planning and delivering storytimes. 
The post-apprenticeship interviews were conducted following the spring storytime series. Therefore participants had the opportunity to design and deliver six weeks' worth of storytimes independently. When asked what kind of resources they utilized to develop their storytime they indicated they looked through the storytime manual, storytime blogs that have been created by other Children's Librarians, and consulted with their peers for activity suggestions. This reinforces the exploration phase of the cognitive apprenticeship. The librarian provided the participants with quality resources to explore activities to include in their storytimes. The participants then browsed these resources to incorporate quality, early literacy based activities in their storytimes. Additionally, by consulting with their peers, participants were engaged in an informal community of practice.

Since participants delivered their storytimes completely on their own and had a new group of kids in their classes, they encountered some difficulties that did not occur during the cognitive apprenticeship. Classroom management was the most difficult to adapt to. In these cases, participants referred to the mentor and their peers for suggestions for how to manage bad behavior in the classroom when parents were not intervening. When asked if they experienced anything during the storytimes that they wished had been covered during the cognitive apprenticeship, participants responded:

I guess, just maybe management... more management. Um, I think the mentorship prepared me for basic management skills, but last session I had a real doosy of a kid. So... um, who you know would push kids and um, but you know, but during the mentorship observation, I didn't see that. It's hard. I mean you can anticipate and you can hypothetically speaking doing this and you can talk about it, but it's difficult when you are in the heat of the moment and the kid is actually pushing and hitting... (Participant 2)

When asked how they handled that particular situation, Participant 2 shared:

I rewarded him when he was doing the right thing. So I praised him by name, pointed out what the other kids were doing right and rewarded the other kids. He wanted a shaker but he wasn't listening, I would give the other kids the shaker and who that they were modeling the right behavior, ask him to model it, and when he did, I would reinforce it with something. Like when he was pushing the kids to get in line for the shakers, asking him to apologize or try again nicely and then give him a shaker.

During the post-interview, we asked the participants for feedback regarding the inclusion of classroom management during the cognitive apprenticeship:

I think with something like this mentorship, really the only way I learned those things was a peer, or modeling and seeing it, or just some tips, like um reflecting this was what went wrong during my storytime. Because when I was in the classroom, that's kind of how I did it. Ok, this is what he's doing, so try this. So, I don't know, maybe bouncing ideas off of peers. I know Susie was like, I had a kid like that and this is what worked, or you know if there's a management training, people just sharing their experiences. I just... when I was in those situations in a classroom setting, my peers were the best, because they would share things that worked. (Participant 2)

Participant 2 experienced multiple phases of the cognitive apprenticeship throughout this ordeal. When she tried to fix the behavior problem on her own, she reflected on what she was previously 
doing, what the cause of the problem was, and how to ultimately change the behavior. She identified the problem and possible solutions, in the "heat of the moment". When she recognized that what she was doing was not working, she then consulted her peers and her mentor for more suggestions for how to handle the behavior. This is part of the informal community of practice and coaching. Therefore, cognitive apprenticeships in a workplace setting do not end. The mentor continues to serve in a coaching role when the mentee encounters a novel problem that they cannot solve on their own. Additionally, the community of practice should continue as a resource for mentees to consult when they encounter these problems as well.

\section{Recounts from Librarian Reflections}

The librarian found that the cognitive apprenticeship must be altered and adapted based on the learner's previous experience. For example, since Participant 2 had experience teaching and some experience with planning and delivering library programs, she was quicker to demonstrate understanding of the curriculum and integrating it into her storytime. She was also more confident in her delivery abilities and therefore the cognitive apprenticeship was altered to allow her to begin presenting sooner. Whereas, Participant 3 had very little programming or teaching experience, she needed to go through the whole cognitive apprenticeship, and even acknowledged the fact that she would need further practice before feeling completely comfortable presenting storytimes in front of an audience on her own.

In terms of carrying out the cognitive apprenticeship, the librarian found it easy to justify each phase of the training. She was able to verbally express why she chose the elements contained in the storytime presentation and how they are associated with each of the early literacy skills found in the ECRR curriculum. Once the learner demonstrated an understanding of the program structure, the librarian allowed the programmer to alter parts of the program such as creating the callouts and choosing the books.

The most difficult aspect of the cognitive apprenticeship was providing opportunities for the participants to reflect on the process of planning their storytimes. While the part0icipants were choosing materials that were similar to materials the librarian previously chose, the librarian had to prod the programmer for more information about why they chose the material. For example, there were times the programmer chose a book that was similar to the original book chosen by the librarian, but was not appropriate for the age group or for storytime. In these cases, the librarian would provide the programmer with constructive feedback and reasons as to why the material was inappropriate and the programmer would try again.

Participants expressed that they were not given enough experience prepping the storytime at the beginning of the six week series. "I felt like I didn't get the experience of prepping. Maybe at the beginning when everyone is prepping to build the storytime together instead of using the mentor's structure with explanation. Be more involved in the planning." Simply being presented with the initial structure along with an explanation is not enough. Therefore it is recommended that mentees be brought into the cognitive apprenticeship much earlier when the initial structure of the storytime is created and have them work alongside the mentor. This would suggest that the cognitive apprenticeship may not be linear, forcing the mentee to go through each stage of the 
apprenticeship. Instead, the instructor is able to combine stages. For example, should the mentor and mentee develop the structure together then modeling, scaffolding, and coaching would all be included in the same stage.

During the 3 month interview, participants indicated that they would have liked to discuss and learn from other participants. When asked what they would have changed about the cognitive apprenticeship, participant 2 shared:

Maybe talking to others who are going through the program? Like, I would like to hear what maybe [Participant 3] and anyone else who went through it and um, the sharing.

Participant 3 also indicated a similar sentiment. This need for peer support can be met through the inclusion of a formal community of practice.

This substantiates the community of practice aspect of the cognitive apprenticeship model. While participants had an unofficial community of practice by tapping into their peers' knowledge and experience, a more formal venue for discussion may be needed for participants to talk about their experiences as well as what books and songs to use for various age groups, especially considering participants were at different locations within the city.

\section{Discussion}

Both mentorships and cognitive apprenticeships begin by stating a goal, regardless of whether the mentor, mentee, or both together set the goal. In the case of this study the overall goal of training the participants was set by the department and therefore the mentor. The initiation of the relationship between the programmer and the librarian was matched up by the manager of the youth and family services department by identifying individuals who required training to provide storytimes and a librarian who had the necessary skillset to successfully guide, coach, and mentor the participants.

The next stage of the mentorship model is initiation, which is where the mentor and mentee outline their expectations of the relationship (Kram, 1983, Newby \& Heide, 1992). During the implementation of the cognitive apprenticeship for this study, the librarian outlined the goals for the apprenticeship as well as outlined how the apprenticeship would be structured from beginning to end. As soon as an understanding was met regarding the goals of the cognitive apprenticeship, the librarian and programmer jumped right into the cognitive apprenticeship or the cultivation stage.

The cultivation stage of mentorship is essentially when the mentor observes the mentee and provides feedback. This is the point in which the stages of the cognitive apprenticeship are put into play: modeling, coaching, scaffolding, articulation, reflection, and exploration. Therefore, the majority of the cognitive apprenticeship takes places within the cultivation stage of the overall mentorship.

Finally, separation during both the mentorship and the cognitive apprenticeship occurs once the novice has gained enough experience from the expert to be able to perform the job on his or her 
own. Whereas as the aim of a traditional mentorship is to cultivate an individual's talent for organizational purpose, and therefore separation typically occurs years after initiation, during a cognitive apprenticeship, separation may occur as soon as the learner has mastered the learning objects outlined by either the organization or the expert. Therefore, a cognitive apprenticeship may be seen as a 'mini-mentorship,' based on short term goals such as learning a new skill.

Formal mentorship programs look to cultivate an individual to meet long term goals or participation within an organization. The mentorship discussed in this paper is designed to meet mentor and mentee short term goals such as learning a new skill. As formal mentorship and cognitive apprenticeships share many defining attributes, they can be combined to enhance a novice's training experience to increase confidence and increase sustainable learning by placing the training and mentorship in an authentic, situated learning environment. Few studies on the development of cognitive apprenticeships have focused all six aspects of a cognitive apprenticeships in its entirety. This study attempted to include as many as possible and acknowledges the lack of a formalized community of practice as discussed below.

\section{Modeling}

According to Bandura (1971) learners who observe activities of an expert will internalize the material and develop a visual model the learner can retrieve when presented with a similar or novel situation. Additionally, Jonassen (1999) identified two types of modeling: behavioral and cognitive. In essence, behavioral modeling 'showing' an individual how to do something. Cognitive modeling on the other hand, is explaining the thought process involved in solving a problem.

In the design of the cognitive apprenticeship, the librarian modeled her cognitive processes for all aspects of planning and delivering the storytime classes. Think aloud protocols were put into place to explain how the librarian chose the books, activities, songs, and callouts. Additionally, during the first two weeks of the cognitive apprenticeship, the librarian modeled the delivery of the storytime. Following the storytime, the librarian further explained why she chose the structure and the classroom management techniques to manage behaviors.

\section{Coaching}

Coaching as defined by Collins, et al., 1989 is observing the learner and providing feedback as needed in order to help the learner reach the level of the expert. Collins, et al. suggest that coaching is interwoven throughout the entire cognitive apprenticeship. Coaching as defined by the mentorship literature is the ability to help the mentee reach the goals outlined by the mentor and mentee (Newby and Heide, 1992). Coaching strategies that were built into the cognitive apprenticeship include debriefing sessions following each step. For example, when the programmer was responsible for planning part of the storytime, the librarian debriefed the programmer in order to gain insight into the reasons why books were chosen, or to give feedback following a program. This was the point in time in which the librarian reinforced the aspects that met expectations, as well as providing feedback and information regarding behaviors that could be modified. 


\section{Scaffolding}

Scaffolding is defined as placing strategies in place to help the learner complete tasks on their own (Brown, Collins, \& Duguid, 1989; Vygotsky, 1986)). In the case of this cognitive apprenticeship, the overall structure was based on scaffolding. At the beginning of the cognitive apprenticeship learners were directed to observing and asking questions. During weeks three and four, the learner was asked to begin planning aspects of the storytime on their own. Then during weeks five and six the learner was asked to completely plan the storytime on their own and was provided feedback in order to enhance the quality of the materials utilized. Therefore, the learner began with having a lot of help from the librarian to only begin provided with feedback at the end.

Throughout the cognitive apprenticeship, scaffolding was used in order to help programmers plan and deliver the storytimes independently. The main aspect in which scaffolding was utilized was in the placement of the three parental callouts, as this was the most difficult aspect of storytime planning and delivering for all three participants. Oftentimes the librarian asked the programmers questions to direct them for the proper placement. Scaffolding was utilized to help programmers choose age appropriate books. The librarian would bring attention to the wordiness on the page or the style of the pictures to help the programmers determine the appropriateness of the book for the storytime.

\section{Articulation}

Articulation is defined as the ability to verbalize the learner's knowledge (Collins, Bown, \& Newman, 1987; McLellan, 1994). This was accomplished through a think aloud strategy in which the programmer had to discuss how they reached the decision to include the books, activities, songs, and parental callouts during the storytime planning process. During the planning meetings between the librarian and the programmer, the programmer would show the librarian the materials they have chosen for their program. The librarian then would ask questions such as "Why did you choose this book for your program?" in order to determine whether or not the programmer was using the logic discussed during the modeling phase of the cognitive apprenticeship, and understood fully the reason why so much thought went into the planning of the program.

\section{Reflection}

Reflection refers to the learner's ability to compare their performance with the performance of the expert (Brown et al., 1989; Collins, Bown, et al., 1987; Schon, 1987). This is the one aspect of that was not formally part of the design of this cognitive apprenticeship. It is important to note that while programmers were articulating their knowledge while planning their storytimes, they would often utilize phrases such as: I placed my model callout after singing the alphabet song because we were talking about letter knowledge, "like you did." Therefore, it may be important to 
note there is little distinction between reflection and articulation; or, at the very least, articulation and reflection occur simultaneously.

\section{Exploration}

Exploration refers to the learner's ability to problem solve on their own by exploring possible solutions and using all resources available to them (Brown et al., 1989; Collins, Bown, et al., 1987). In this cognitive apprenticeship, the librarian provided the programmer with a list of resources in order to explore books, songs, parental callouts and other activities to be incorporated in the storytime program. While the librarian planned the storytime during weeks one and two, the storytime programmer was responsible exploring these resources in order to locate age appropriate elements into the storytime program.

\section{Limitations}

A limitation of this study was the small sample size. This is one cognitive apprenticeship design with three participants, two of which completed the entire study in a specific research environment: libraries. Therefore generalizability is limited to other learning environments.

A second limitation was the amount of time allocated for the cognitive apprenticeship. During this study, the researchers had to complete the cognitive apprenticeship over the course of six weeks due to the amount of time the library was able to offer new librarians for storytime procedures. Due to the small number of participants in the cognitive apprenticeship, the researchers were able to carefully construct a mentoring experience and provide one-to-one support when needed. If additional research is conducted exploring the amount of time allocated for conducting cognitive apprenticeships, careful consideration will be needed regarding the number of participants to ensure their needs are met.

Finally, the number of opportunities to observe participants following the cognitive apprenticeship to ensure longevity of training were limited. While participants and the librarian worked closely during the six weeks of the training, participants were left to plan and implement programming entirely on their own, with the exception of coaching when the programmer took the initiative. Due to time and schedule constraints, the only opportunity to observe the programmer's storytime delivery was during the department's mandatory series observation, which occurs at the end of a six weeks' series to evaluate whether a programmer is meeting the programming standards of the department.

\section{Instructional Design Implications}

In order for learners to get the most out of their cognitive apprenticeship experience, the instructional designer must evaluate the learner's prior knowledge and background in order for the experience to be meaningful. Additionally, the instructional designer should take time to reflect on the learner's progress during each stage of the cognitive apprenticeship to evaluate the 
learner's progress and to determine whether or not the learner requires additional scaffolded practice or coaching before support can be faded out. This can be determined by analyzing the learner's reflections on their experience and how they articulate their knowledge and understanding of why they are making the decisions they are making.

As the author noted, the expert librarian had a difficult time encouraging the novices to articulate and reflect on their understanding and experiences within the cognitive apprenticeship. It might be useful to encourage not only the expert to keep a reflective journal of the experience but for the novices to do the same. The expert may even provide a list of suggested questions to encourage the learner to think about their experience, instead of reflecting with no guidance.

Should the expert take on more than one novice at a time, the instructional designer should ensure there is enough time allotted to give each individual participant enough attention to be able to adapt the cognitive apprenticeship based on the level of the novice. It may be possible to pair novices together based on their zone of proximal development (Vygotsky, 1981) so novices can learn from each other and support one another. This may be an option to alleviate the additional time and workload of the expert that is needed to ensure each novice is receiving a meaningful experience.

\section{Future Research}

As participants noted, the most important aspect of the cognitive apprenticeship experience was modeling, as this set the stage for expectations and understanding of the tasks. Future research should be conducted on the best approach to model cognitive processes both for in person cognitive apprenticeships and those that are carried out in an online environment.

Multiple participants indicated a need for communication and support from other members who participated in the cognitive apprenticeship. Additional research should be conducted into a formal community of practice with possible knowledge management and capture aspects to aid in the professional development of both current and future storytime programmers, especially for library systems that have multiple branches and high turnover.

An additional component of the cognitive apprenticeship framework is community of practice. While this component was not officially part of this study, future research can be conducted to determine what kind of format encourages knowledge sharing and use of a community of practice.

\section{Conclusion}

As libraries move toward early literacy, curriculum based storytimes aimed at educating both the child and the caregiver, it has become increasingly important to train programmers to be educators, especially for those who do not have an education background. A training program based on the cognitive apprenticeship model allows the programmer to learn directly from an individual who is considered to be an expert in providing these structured and curriculum based storytimes. While there is limited empirical studies utilizing the cognitive apprenticeship 
framework in its entirety, the results are promising. Future research on the alignment between mentorship and cognitive apprenticeship is needed to attempt to enhance on-the-job, situated, authentic learning.

\section{References}

Block, P. (2011). Flawless consulting: A guide to getting your expertise used ( $3^{\text {rd }}$ ed.). Hoboken, NJ: Pfeiffer.

Alger, C., \& Kopcha, T. J. (2011). Technology supported cognitive apprenticeship transforms the student teaching field experience: Improving the student teaching field experience for all triad members. The Teacher Educator, 46, 71-88.

Bandura, A. (1971). Social learning theory. New York: General Learning Press.

Block, P. (2011). Flawless Consulting: A guide to getting your expertise used (3rd ed.). San Francisco: Pfeiffer.

Bouta, H., \& Paraskeva, F. (2013). The cognitive apprenticeship theory for the teaching of mathematics in an online 3D virtual environment. International Journal of Mathematical Education in Science \& Technology, 44(2), 159-178.

Brown, J. S., Collins, A., \& Duguid, P. (1989). Situated cognition and the culture of learning. Educational Researcher, 18(1), 32-42.

Collins, A., Bown, J. S., \& Newman, S. E. (1987). Cognitive apprenticeship: Teaching the craft of reading, writing, and mathematics. Hillsdale, NJ: Lawrence Erlbaum Associates.

Collins, A., Brown, J. S., \& Holum, A. (1991). Cognitive apprenticeship: Making thinking visible. American Educator, 15(3), 1-18.

Collins, A., Hawkins, J., \& Carver, S. M. (1991). A cognitive apprenticeship for disadvantaged students. In B. Means, C. Chelemer, \& M. S. Knapp (Eds.), Teaching advanced skills to at-risk students (pp. 216-243). San Francisco: Jossey-Bass.

Delattre, M., Ocler, R., Moulette, P., \& Rymeyko, K. (2009). Singularity of qualitative research: From collecting information to producing results. Journal of Critical Postmodern Organization Science, 73(3), 33-50.

Dennen, V. P. \& Bruner, K. J. (2007). Cognitive apprenticeship in educational practice: Research on scaffolding, modeling, mentoring, and coaching as instructional strategies. In D. H. Jonassen, M. J. Spector, M. Driscoll, M. D. Merrill, \& J. van Merrienboer (Eds.), Handbook of research for educational communications and technology (pp. 426-437). Hillsdale, NJ: Erlbaum.

Dickey, M. D. (2008). Integrating cognitive apprenticeship methods in a web-based educational technology course for P-12 teacher education. Computers \& Education, 51, 506-518.

Gilley, A., Gilley, J. W., \& Kouider, E. (2010). Characteristics of managerial coaching. Performance Improvement Quarterly, 23(1), 53-70. doi:10.1002/piq.20075

Higgins, M. M. \& Kram, K. E. (2001). Reconceptualizing mentoring at work: A developmental network perspective. The Academy of Management Review, 26(2), 264-288. 
Jonassen, D. H. (1999). Designing constructivist learning environments. In Reigeluth (Ed.), Instructional design theories and models (pp. 217-239). Mahwah, NJ: Lawrence Erlbaum Associates.

Joo, B. (2005). Executive coaching: A conceptual framework from an integrative review of practice and research. Human Resource Development Review, 4(4), 462-488. doi:10.1177/1534484305280866

Kram, K. E. (1983). Phases of the mentor relationship. The Academy of Management Journal, 26(4), 608-625.

Larkin, M., Watts, S., \& Clifton, E. (2005). Giving voice and making sense in Interpretative Phenomenological Analysis. Qualitative Research in Psychology, 3(2), 102-120.

Lave, J. (1988). Cognition in Practice: Mind, mathematics and culture in everyday life. London: Cambridge University Press.

Liu, T. C. (2005). Web-based cognitive apprenticeship model for improving pre-service teachers' performances and attitudes towards instructional planning: Design and field experiment. Journal of Educational Technology \& Society, 8(2), 136-149.

McLellan, H. (1994). Situated learning: Continuing the conversation. Educational Technology, 34(10), 7-8.

Newby, T. J. \& Heide, A. (1992). The value of mentoring. Performance Improvement Quarterly, 5(4), 2-15. doi:10.1111/j.1937-8327.1992.tb00562.x

Raabe, B. \& Beehr, T. A. (2003). Formal mentoring versus supervisor and coworker relationships: Differences in perceptions and impact. Journal of Organizational Behavior, 24, 271-293. doi:10.1002/job.193

Schon, D. A. (1987). Educating the Reflective Practitioner. San Francisco: Jossey-Bass Inc., Publishers.

Stewart, K. K. \& Lagowski, J. J. (2003). Cognitive apprenticeship theory and graduate chemistry education. Journal of Chemical Education, 80(12), 1362-1367.

Swap, W., Leonard, D., Shields, M., \& Abrams, L. (2001). Using mentoring and storytelling to transfer knowledge in the workplace. Journal of Management Information Systems, 18(1), 95-114.

Vygotsky, L. (1986). Thought and language. Cambridge, MA: MIT Press.

Willig. C. (2008). Introducting qualitative research in psychology: Adventures in theory and method ( $2^{\text {nd }}$ ed.). Maidenhead, England: McGraw Hill/Open University Press.

Correspondence: Jill E. Stefaniak, Assistant Professor, Instructional Design and Technology Program, Department of STEM Education and Professional Studies, Darden College of Education, Old Dominion University, Norfolk, Virginia, United States of America 